\title{
Psychological factors that affect mental resilience in crises
}

\author{
Mustafa Elsaied Esmail ${ }^{1 *}$, Abdul Baqi Mansour Bukhary ${ }^{2}$, Abdulaziz Khalid Addas ${ }^{1}$, \\ Maaz Ahmed Raei ${ }^{1}$, Abdullah Abdulrahman Alzayed ${ }^{3}$, Yahya Mohammad Alreemi ${ }^{4}$, \\ Yousef Shamlan Al Harban ${ }^{5}$, Shakr Fawaz Alwani', Tameem Ahmed Alfuraih ${ }^{3}$, \\ Ali Hassan Alhawaj ${ }^{7}$, Muhannad Saad Alzahrani ${ }^{8}$
}

\author{
${ }^{1}$ Department of Psychiatry, Eradah Al Amal Mental Health Complex, Jeddah, Saudi Arabia \\ ${ }^{2}$ College of Medicine, Taibah University, Medina, Saudi Arabia \\ ${ }^{3}$ College of Medicine, King Saud bin Abdulaziz University for Health Sciences, Riyadh, Saudi Arabia \\ ${ }^{4}$ Department of Psychiatry, King Abdulaziz Hospital, Mecca, Saudi Arabia \\ ${ }^{5}$ College of Medicine, Royal College of Surgeons in Ireland-Medical University of Bahrain, Muharraq, Bahrain \\ ${ }^{6}$ College of Medicine, King Saud bin Abdulaziz University for Health Sciences, Jeddah, Saudi Arabia \\ ${ }^{7}$ Department of Psychiatry, Eradah Al Amal Mental Health Complex, Dammam, Saudi Arabia \\ ${ }^{8}$ College of Medicine, University of Jeddah, Jeddah, Saudi Arabia
}

Received: 25 November 2021

Accepted: 10 December 2021

\section{*Correspondence:}

Dr. Mustafa Elsaied Esmail,

E-mail: Muustafa8011@yahoo.com

Copyright: ( ) the author(s), publisher and licensee Medip Academy. This is an open-access article distributed under the terms of the Creative Commons Attribution Non-Commercial License, which permits unrestricted non-commercial use, distribution, and reproduction in any medium, provided the original work is properly cited.

\begin{abstract}
Psychopathological morbidities represent a significant burden over the different sectors of populations exposed to the different crises. Many factors can contribute to the development of these events, including economic, health-related, and psychological factors. In addition, different factors can affect resilience, including demographic, environmental, and psychological factors. Many original studies have highlighted the impact of these factors on resilience in these settings. In the present literature review, we discussed the different psychological factors associated with resilience following a crisis. Some factors include the sense of avoidance and fear of being harmed or impacted by these crises. Our findings indicate the impact of different factors on psychological resilience during these events. For instance, reports show that fear of catching and transmitting the infection during infectious diseases pandemics was associated with reduced resilience and increased anxiety and stress. On the other hand, lockdown measures were associated with better resilience. In addition, social support, coping strategies, and adequate training and experience are essential factors that significantly contribute to resilience in a crisis.
\end{abstract}

Keywords: Crisis management, Psychology, Resilience, Coping, Distress, Anxiety, Stress, Pandemics

\section{INTRODUCTION}

The incidence of natural disasters is increasing with time, owing to different factors, especially climate changes. Furthermore, there have also been different pandemics of infectious diseases during the past decades, adding to the burdens on the different global communities. ${ }^{1,2}$ In addition, evidence from different studies in the literature has highlighted the significant risk of developing major psychological disorders following these events. Some reported events include post-traumatic stress disorder, stress, and anxiety. ${ }^{3-5}$ Moreover, evidence indicates that social and economic factors might also contribute to psychopathology and impact the quality of life of the affected individuals. Accordingly, it is essential to introduce urgent management and interventional modalities for populations at high risk of suffering from these burdens.

Among the different interventions, resilience and coping with the different stressors have been reported with 
enhanced outcomes and quality of life during crises. ${ }^{6,7}$ However, it should be noted that different factors can affect resilience, including demographic, environmental, and psychological factors. Many original studies have highlighted the impact of these factors on resilience in these settings. ${ }^{8,9}$ Therefore, based on evidence from previous studies, the present literature review will discuss the different psychological factors that can potentially impact resilience during a crisis.

\section{LITERATURE REVIEW}

This literature review is based on an extensive literature search in Medline, Cochrane, and EMBASE databases which was performed on $25^{\text {th }}$ October 2021 using the medical subject headings (MeSH) or a combination of all possible related terms, according to the database. To avoid missing potential studies, a further manual search for papers was done through Google Scholar while the reference lists of the initially included papers. Papers discussing psychological factors that affect mental resilience in crises were screened for useful information. No limitations were posed on date, language, age of participants, or publication type.

\section{DISCUSSION}

As a result of the exposure to different stressors in recent years, evidence shows that populations tend to develop different resilience factors to cope with the different stressors and enhance their quality of life. Therefore, many investigations aimed to investigate these factors and draw better interventions to enhance the outcomes in this context. In this context, a previous study assessed the different factors associated with resilience against pandemics after exposing their population to two weeks of stress. The authors reported that an upbeat appraisal style was significantly associated with resilience. It has been furtherly reported that stress response recovery was a significant psychological factor associated with resilience. $^{10}$

Another investigation in Nepal aimed to assess the impact of psychological factors on resilience among patients with earthquake-related spinal cord injuries. The authors reported that having a depressive mood and self-efficacy were significantly correlated with an impact on the resilience among the included participants. It has been furtherly demonstrated that resilience was also significantly influenced by the employment status of the participants, current living location, and sex. In addition, social support was also significantly associated. However, by multi regression analysis, it was not. Besides, spirituality did not have a significant association with resilience among the included patients. Another investigation that obtained their data following September 11, 2001 terrorist attack also aimed to assess the correlation between different factors and resilience. It has been reported that having past and recent life stressors, the number of comorbid and chronic conditions, social support, income change, level of exposure to the traumatic disorder were associated with resilience. Moreover, the authors reported that education, ethnicity and race, age, and gender were all significant factors associated with resilience after these events. ${ }^{11}$

Evidence shows that having a sense of preparedness and competence is significantly associated with better resilience outcomes. Accordingly, these outcomes are more significant among individuals that perceive more preparedness and training to cope with crisis-related events. In addition, these patients are reported to have a reduced risk of developing mental health manifestations. Following the 2004 Madrid bombings, a previous investigation by Gabriel et al aimed to assess different psychological factors associated with resilience among police officers. ${ }^{12}$ Among the included population, it has been reported that only two officers said that they had depressive symptoms without any other mental manifestations. The low prevalence of depressive symptoms among the included population has been attributed to the fact that most of them were adequately prepared to deal with such attacks. In this context, the authors reported that most participants $(70 \%)$ received terrorist operation modules. The impact of training and preparedness was also indicated by previous investigations that showed that depressive symptoms and resilience were significantly enhanced among trained personnel than volunteering individuals. ${ }^{13-15}$ Following the 2004 South East Asia tsunami, another investigation reported that reduced stress-related events were significantly associated with specific training and mission preparation programs. ${ }^{16}$ Similar findings were also reported among individuals that developed post-traumatic distress syndrome. ${ }^{17}$

The impact of training and preparedness was also assessed among healthcare workers during outbreaks and pandemics. For instance, a previous study reported that resilience against mental health manifestations was significantly associated with receiving adequate experience and training during the SARS outbreak. ${ }^{18}$ Other similar investigations have furtherly reported this. In addition, a previous study that was conducted during the same period also reported that poor mental health was significantly reduced among healthcare family physicians that received training courses about the proper management of cases during an outbreak of infectious diseases. ${ }^{19}$ In the same context, it has been reported that reduced adverse psychological events and decreased stress levels were significantly associated with healthcare workers who are confident about their skills and knowledge about infection control practices. These events were evident among these workers more than other workers who had lower confidence levels during the SARS outbreak. ${ }^{20}$ During COVID-19, different factors were also reported to affect resilience and reduce the frequency of developing psychological symptoms. It has been demonstrated that enhanced resilience was associated with social distancing measures, while general 
bad health conditions were associated with high-stress levels. ${ }^{21}$ Different factors were reported to contribute to the levels of stress during the COVID-19 pandemic. These factors include reduced confidence in avoiding COVID-19 and having a feeling of vulnerability in catching COVID-19. ${ }^{21}$ This has been further indicated in previous investigations that reported that feelings of anxiety and other psychological parameters were significantly associated with fearing catching an infection or transmitting it to other individuals in society. ${ }^{22-25}$ Lower meaning in life and high distress levels were also significantly influenced by reduced confidence in avoiding infections, job insecurity, and income reduction during the COVID-19 pandemic. $^{21}$

A previous study also reported reduced mental health manifestations that included nurses working in SARS after perceiving adequate family support. ${ }^{26}$ During the Hurricane Katrin crisis, Tak et al investigation demonstrated that reduced depressive symptoms among fire-fighters were associated with living with families. ${ }^{27}$ In addition to community and social support, evidence shows that perceiving adequate support from managers and colleagues was also previously evidenced to reduce the frequency and intensity of mental health disorders. A previous study demonstrated reduced anger states and avoidance behaviors were significantly associated with providing adequate organizational support for the included nurses during the SARS crisis. ${ }^{28}$ A previous study in Australia assessed factors associated with resilience following a major flood among police officers in this context. It has been reported that reduced psychological strain was significantly associated with providing adequate supervisor and cultural support to the included officers. ${ }^{29}$ Thus, evidence of the efficacy of social support has been provided for the public and military individuals. ${ }^{30}$ Evidence furtherly indicates that resilience is significantly associated with social, family, and friends support. The previous study that was recruited police officers that witnessed Madrid bombings also indicated that social support was also associated with the reduced frequency of psychopathological events and provided adequate training for these individuals. ${ }^{12}$ Evidence among Humanitarian aid workers also reported that social support was associated with enhanced life satisfaction and reduced burnout, psychological distress, and depression. ${ }^{31}$ Following the 2005 North Pakistan earthquake, evidence indicated that social support was significantly associated with reduced burnout, depression, anxiety, and post-traumatic distress. ${ }^{32}$ Previous studies based on data following the 9/11 attacks demonstrated that social support and self-confidence were associated with the different psychopathological parameters of these crisis-related events. ${ }^{33}$ These findings imply the importance of community support to the different workers and populations directly related to and are at significant risk of developing psychopathological morbidities.

Among the different factors associated with resilience during a crisis is the presence of effective coping strategies. For example, it has been reported that posttraumatic stress was significantly associated with having an approach acceptance attitude towards mortality among crisis workers. In addition, negative psychological impacts were significantly associated with avoiding fear of death and avoiding thinking of death. On the other hand, it has been demonstrated that resilience was significantly associated with thinking of the traumatic events rather than avoiding them and accepting their potential incidence. Previous investigations have indicated these findings that showed that psychopathology was associated with a feeling of avoidance of thinking about stress-related events and mortality. Previous studies have indicated that individuals exposed to stress-related events have reduced psychological manifestations when they cope with the different stressors and convince themselves about their abilities to deal with the different crisis-related events. ${ }^{34-36}$

Previous similar investigations also reported that selfefficacy is a significant factor that can influence resilience. This psychological factor is essential to promote and motivate individuals following crises and enhance their health-promoting behaviors. Therefore, it has been demonstrated that reduced psychological behaviors were associated with high self-confidence to pass through the different crisis-related stressors and better with these situations without being impacted by the adverse outcomes. In this context, a previous study concluded that resilience was significantly associated with being highly confident of having control over the different desirable things. ${ }^{37}$

Low resilience was reported to be significantly associated with having a depressive mood. ${ }^{38-40}$ The presence of a crisis-related event can significantly lead to various factors that lead to developing a depressive mood. These factors include chronic pain, being less dependent on performing daily activities, financial and employment loss, difficulty with reintegration and adjustment into the community and routine life, and restricted mobility among patients who suffer from crisis-related injuries. ${ }^{41,42}$ For instance, a previous study showed that crisis-related injuries influenced patients to develop suicidal thoughts and ideas, have more frequent hospital visits, and develop an increased risk of medical complications. Affected individuals might also reduce the frequency of performing exercises, avoiding eating and self-care activities. These factors were reported to increase depressive mood characteristics associated with low resilience against crises. ${ }^{43-45}$

Among individuals that survive disasters, evidence shows that social support is a significant factor of resilience and coping among these patients. ${ }^{37,39,46}$ However, other studies reported that this factor is not significant among their participants following disasters. Thus, social support does not enhance the person's ability to buffer the different crisis-related stressors. On the other hand, it has improved resilience among the affected personnel. ${ }^{11,47}$ 
A previous study also demonstrated that enhanced resilience parameters were significantly associated with confidence-related various internal factors. ${ }^{48}$ These factors have been reported to regulate the emotions and thoughts of individuals after the crises. The impact of spirituality on resilience outcomes and coping was also reported among previous investigations. However, evidence is contradicting about its significance in this context. ${ }^{37}$ These differences can be attributed to different reasons. For instance, the cause of injury following the crisis and the duration of living with such impacts might alter the individuals' spirituality. It is widely known that different circumstances can significantly affect spirituality because it is mainly dynamic. ${ }^{49,50}$ Therefore, it might be challenging to assess the association between spirituality and resilience from cross-sectional investigations. Therefore, this might explain why the association between spirituality and resilience is different among cross-sectional designs. Accordingly, other investigations with better designs are needed for better validation.

\section{CONCLUSION}

Psychopathological morbidities represent a significant burden over the different sectors of populations exposed to the different crises. Many factors can contribute to the development of these events, including economic, healthrelated, and psychological factors. In the present literature review, we discussed the different psychological factors associated with resilience following a crisis. Our findings indicate the impact of different factors on psychological resilience during these events. Some factors include the sense of avoidance and fear of being harmed or impacted by these crises. For instance, reports show that fear of catching and transmitting the infection during infectious diseases pandemics was associated with reduced resilience and increased anxiety and stress. On the other hand, lockdown measures were associated with better resilience. Social support, coping strategies, and adequate training and experience are essential factors that significantly contribute to resilience in a crisis.

Funding: No funding sources Conflict of interest: None declared

Ethical approval: Not required

\section{REFERENCES}

1. Guha-Sapir D, Hoyois P, Below R, Vanderveken A. Annual Disaster Statistical Review 2015: The numbers and trends. 2016.

2. Sandler T. The analytical study of terrorism: Taking stock. J Peace Res. 2014;51(2):257-71.

3. Neria Y, Nandi A, Galea S. Post-traumatic stress disorder following disasters: a systematic review. Psychological medicine. 2008;38(4):467-80.

4. Tracy M, Norris FH, Galea S. Differences in the determinants of posttraumatic stress disorder and depression after a mass traumatic event. Depression anxiety. 2011;28(8):666-75.

5. Tol WA, van Ommeren M. Evidence-based mental health and psychosocial support in humanitarian settings: gaps and opportunities. Evidence-based mental health. 2012;15(2):25-6.

6. Patel SS, Rogers MB, Amlôt R, Rubin GJ. What Do We Mean by 'Community Resilience'? A Systematic Literature Review of How It Is Defined in the Literature. PLoS currents. 2017;9.

7. Luthar SS. Resilience in development: A synthesis of research across five decades. 2006.

8. Manyena SB. The concept of resilience revisited. Disasters. 2006;30(4):434-50.

9. Rodriguez-Llanes JM, Vos F, Guha-Sapir D. Measuring psychological resilience to disasters: are evidence-based indicators an achievable goal? Environmental health : a global access science source. 2013;12:115.

10. Veer IM, Riepenhausen A, Zerban M. Psycho-social factors associated with mental resilience in the Corona lockdown. Translational Psychiatry. 2021;11(1):67.

11. Bonanno GA, Galea S, Bucciarelli A, Vlahov D. What predicts psychological resilience after disaster? The role of demographics, resources, and life stress. J consulting clin psychol. 2007;75(5):671-82.

12. Gabriel R, Ferrando L, Cortón ES. Psychopathological consequences after a terrorist attack: an epidemiological study among victims, the general population, and police officers. Euro psychiatry. 2007;22(6):339-46.

13. Hagh-Shenas H, Goodarzi MA, Dehbozorgi G, Farashbandi H. Psychological consequences of the Bam earthquake on professional and nonprofessional helpers. J traumatic stress. 2005;18(5):477-83.

14. Ersland S, Weisaeth L, Sund A. The stress upon rescuers involved in an oil rig disaster. "Alexander L. Kielland" 1980. Acta psychiatrica Scandinavica Supplementum. 1989;355:38-49.

15. Perrin MA, DiGrande L, Wheeler K, Thorpe L, Farfel M, Brackbill R. Differences in PTSD prevalence and associated risk factors among World Trade Center disaster rescue and recovery workers. Am j psychiatry. 2007;164(9):1385-94.

16. Thoresen S, Tønnessen A, Lindgaard CV, Andreassen AL, Weisaeth L. Stressful but rewarding: Norwegian personnel mobilised for the 2004 tsunami disaster. Disasters. 2009;33(3):353-68.

17. Iversen AC, Fear NT, Ehlers A. Risk factors for posttraumatic stress disorder among UK Armed Forces personnel. Psychol med. 2008;38(4):511-22.

18. Maunder RG, Lancee WJ, Balderson KE. Long-term psychological and occupational effects of providing hospital healthcare during SARS outbreak. Emerging infect dis. 2006;12(12):1924-32.

19. Wong WC, Wong SY, Lee A, Goggins WB. How to provide an effective primary health care in fighting against severe acute respiratory syndrome: the 
experiences of two cities. Am j infect control. 2007;35(1):50-5.

20. Chua SE, Cheung V, Cheung C. Psychological effects of the SARS outbreak in Hong Kong on highrisk health care workers. Can j psychiatry Revue canadienne de psychiatrie. 2004;49(6):391-3.

21. Coulombe S, Pacheco T, Cox E. Risk and Resilience Factors During the COVID-19 Pandemic: A Snapshot of the Experiences of Canadian Workers Early on in the Crisis. Frontiers in Psychology. 2020;11(3225).

22. Maunder R, Hunter J, Vincent L. The immediate psychological and occupational impact of the 2003 SARS outbreak in a teaching hospital. Can Med Asso j. 2003;168(10):1245-51.

23. Hawryluck L, Gold WL, Robinson S, Pogorski S, Galea S, Styra R. SARS control and psychological effects of quarantine, Toronto, Canada. Emerging infect dis. 2004;10(7):1206-12.

24. Reynolds DL, Garay JR, Deamond SL, Moran MK, Gold W, Styra R. Understanding, compliance and psychological impact of the SARS quarantine experience. Epidemiol infect. 2008;136(7):997-1007.

25. Brooks SK, Webster RK, Smith LE. The psychological impact of quarantine and how to reduce it: rapid review of the evidence. The lancet. 2020;395(10227):912-20.

26. Chen R, Chou KR, Huang YJ, Wang TS, Liu SY, Ho LY. Effects of a SARS prevention programme in Taiwan on nursing staff's anxiety, depression and sleep quality: a longitudinal survey. Int $\mathrm{j}$ nursing studies. 2006;43(2):215-25.

27. Tak S, Driscoll R, Bernard B, West C. Depressive symptoms among firefighters and related factors after the response to Hurricane Katrina. Journal of urban health : bulletin of the New York Academy of Medicine. 2007;84(2):153-61.

28. Marjanovic Z, Greenglass ER, Coffey S. The relevance of psychosocial variables and working conditions in predicting nurses' coping strategies during the SARS crisis: an online questionnaire survey. Int j nursing studies. 2007;44(6):991-8.

29. Biggs A, Brough P, Barbour J. Exposure to Extraorganizational Stressors: Impact on Mental Health and Organizational Perceptions for Police Officers. Int J Stress Management. 2014;21:255-82.

30. Jones N, Seddon R, Fear NT, McAllister P, Wessely $\mathrm{S}$, Greenberg N. Leadership, cohesion, morale, and the mental health of UK Armed Forces in Afghanistan. Psychiatry. 2012;75(1):49-59.

31. Lopes Cardozo B, Gotway Crawford C, Eriksson C. Psychological distress, depression, anxiety, and burnout among international humanitarian aid workers: a longitudinal study. PloS one. 2012;7(9):e44948.

32. Ehring T, Razik S, Emmelkamp PM. Prevalence and predictors of posttraumatic stress disorder, anxiety, depression, and burnout in Pakistani earthquake recovery workers. Psychiatry Res. 2011;185(12):161-6.
33. Adams RE, Figley CR, Boscarino JA. The Compassion Fatigue Scale: Its Use With Social Workers Following Urban Disaster. Res social work practice. 2008;18(3):238-50.

34. Linley P, Joseph S. The Positive and Negative Effects of Disaster Work: A Preliminary Investigation. J Loss Trauma. 2006;11:229-45.

35. Zhen Y, Huang ZQ, Jin J, Deng XY, Zhang LP, Wang JG. Posttraumatic stress disorder of Red Cross nurses in the aftermath of the 2008 Wenchuan China Earthquake. Arch psychiatric nursing. 2012;26(1):63-70.

36. Chang CM, Lee LC, Connor KM, Davidson JR, Jeffries K, Lai TJ. Posttraumatic distress and coping strategies among rescue workers after an earthquake. J nervous mental dis. 2003;191(6):391-8.

37. Bhattarai M, Maneewat K, Sae-Sia W. Psychosocial factors affecting resilience in Nepalese individuals with earthquake-related spinal cord injury: a crosssectional study. BMC Psychiatry. 2018;18(1):60.

38. Driver S, Warren AM, Reynolds M. Identifying predictors of resilience at inpatient and 3-month postspinal cord injury. J spinal cord med. 2016;39(1):77-84.

39. Guest R, Craig A, Tran Y, Middleton J. Factors predicting resilience in people with spinal cord injury during transition from inpatient rehabilitation to the community. Spinal cord. 2015;53(9):682-6.

40. Kilic SA, Dorstyn DS, Guiver NG. Examining factors that contribute to the process of resilience following spinal cord injury. Spinal cord. 2013;51(7):553-7.

41. Craig A, Nicholson Perry K, Guest R. Prospective study of the occurrence of psychological disorders and comorbidities after spinal cord injury. Arch physical med rehabilitation. 2015;96(8):1426-34.

42. Rossignol S, Schwab M, Schwartz M, Fehlings MG. Spinal cord injury: time to move? J Neurosci. 2007;27(44):11782-92.

43. Craig A, Nicholson Perry K. Guide for Health Professionals on the Psychosocial Care of People with a Spinal Cord Injury. 2008.

44. Thieu H, Bach Dat B, Nam NH. Antibiotic resistance of Helicobacter pylori infection in a children's hospital in Vietnam: prevalence and associated factors. Minerva medica. 2020;111(5):498-501.

45. Nguyen TM, Huan VT, Reda A. Clinical features and outcomes of neonatal dengue at the Children's Hospital 1, Ho Chi Minh, Vietnam. J clin virol. 2021;138:104758.

46. El-Qushayri AE, Dahy A, Reda A. A closer look to the high burden of the psychiatric disorders among health care workers (HCWs) in Egypt during COVID-19 outbreak: A meta-analysis of 3137 HCWs. Epidemiol health. 2021:e2021045.

47. Ni C, Chow MC, Jiang X, Li S, Pang SM. Factors associated with resilience of adult survivors five years after the 2008 Sichuan earthquake in China. PloS one. 2015;10(3):e0121033. 
48. Dodd Z, Driver S, Warren AM, Riggs S, Clark M. Effects of Adult Romantic Attachment and Social Support on Resilience and Depression in Individuals with Spinal Cord Injuries. Topics in spinal cord injury rehabilitation. 2015;21(2):156-65.

49. Hodge DR. The intrinsic spirituality scale: A new six-item instrument for assessing the salience of spirituality as a motivational construct. J Social Service Res. 2003;30(1):41-61.
50. Son PT, Reda A, Viet DC. Exchange transfusion in the management of critical pertussis in young infants: a case series. Vox Sang. 2021;116(9):976-82.

Cite this article as: Esmail ME, Bukhary ABM, Addas AK, Raei MA, Alzayed AA, Alreemi YM et al. Psychological factors that affect mental resilience in crises. Int J Community Med Public Health 2022;9:443-8. 